\title{
A Longitudinal Study of Cattle Productivity in Intensive Dairy Farms in Central Ethiopia
}

\author{
Rea Tschopp ${ }^{1,2,3 *}$, Gizachew Gemechu ${ }^{3}$, James L. N. Wood ${ }^{4}$ and \\ The ETHICOBOTS Consortium
}

${ }^{1}$ Department of Epidemiology and Public Health, Swiss Tropical and Public Health Institute, Basel, Switzerland, ${ }^{2}$ University of Basel, Basel, Switzerland, ${ }^{3}$ One-Health Unit, Armauer Hansen Research Institute, Addis Ababa, Ethiopia, ${ }^{4}$ Disease Dynamics Unit, Department of Veterinary Medicine, University of Cambridge, Cambridge, United Kingdom

OPEN ACCESS

Edited by:

Douwe Bakker,

Independent Researcher,

Lelystad, Netherlands

Reviewed by:

Florencia Celeste Mansilla,

Instituto Nacional de Tecnología

Agropecuaria (INTA), Argentina

Julio Alvarez,

VISAVET Health Surveillance Centre

(UCM), Spain

${ }^{*}$ Correspondence:

Rea Tschopp

rea.tschopp@swisstph.ch

Specialty section:

This article was submitted to

Veterinary Epidemiology and

Economics,

a section of the journal

Frontiers in Veterinary Science

Received: 22 April 2021

Accepted: 23 July 2021

Published: 12 August 2021

Citation:

Tschopp R, Gemechu G, Wood JLN and The ETHICOBOTS Consortium (2021) A Longitudinal Study of Cattle Productivity in Intensive Dairy Farms in Central Ethiopia.

Front. Vet. Sci. 8:698760 doi: 10.3389/fvets.2021.698760
Ethiopia is witnessing an emergence of intensive urban dairy farming. The aims of this study were to capture cattle productivity parameters in selected intensive dairy farms in and around Addis Ababa (Central Ethiopia). The study is a pre-requisite and baseline for further economic analysis of diseases such as bovine tuberculosis (BTB) and to assess some of the current challenges faced by farm owners for optimal animal performances. Hence, a 3-year longitudinal observational study was conducted for the first time in Ethiopia, in 24 dairy farms with intensive husbandry, including a total of 1,705 dairy animals. Herd characteristics, animal movement, and productivity parameters (fertility, morbidity, mortality) were recorded in a herd-book. Whereas, half the farms saw their animals increase in number over the 3 years, 37.5\% (mainly large farms) saw their herd size decrease. Offtakes accounted for $76.6 \%$ of all animal exits. One hundred and ninety (11.1\%) animals died of natural causes. Highest mortality was observed in young stock (13.9\%). Overall, diseases were the leading cause for death (57.5\%). The majority of calves (69\%) that died, did so within the first week of life. Mean calving interval $(\mathrm{Cl})$ was 483.2 days. Successful conception after artificial insemination (Al) was $66.1 \%$ with Addis Ababa and smaller farms faring worst. Mean time interval from calving to first service was 152 days. Date of birth to first service was 592.2 days and date of birth to first calving was 794.7 days. In conclusion, the study showed sub-optimal productivity performances in intensive dairy cattle and highlighted some of the current gaps and challenges in urban dairy productivity.

Keywords: intensive dairy, Ethiopia, productivity, fertility, mortality, morbidity

\section{INTRODUCTION}

Ethiopia has the largest livestock population in Africa, with an estimated 60 million cattle (1). The great majority of cattle are local zebus while upgraded cattle (exotic breeds and crossbreeds) account for 0.22 and $1.54 \%$, respectively (1). Ethiopia, thanks to its temperate climate, holds large potential for dairy development. Numerous program and policy interventions were implemented in the last decades to develop the dairy sector. As a result the milk production increased steadily from about 927 million liters in 1996 to 3.3 billion liters in $2018(1,2)$.

The Ethiopian Government has promoted a national development strategy of agricultural-led industrialization encouraging the private sector to get more involved in dairy farming (3). This 
resulted in the emergence of private intensive dairy farms of various sizes run as a business, which focused on peri-urban and urban areas in the central highlands, taking advantage of urbanized large markets and the rapidly increasing demand for animal products such as milk $(4,5)$. Traditionally mainly located in and around Addis Ababa, intensive dairy farms are currently emerging in various locations in the Ethiopian Highlands $(6,7)$. Intensive commercial dairy farming is based on upgraded cattle breed, mainly Holstein-Friesian $\times$ Zebu, improved services and purchased conserved feed $(8,9)$. Almost all of the fluid milk supplied to major urban and peri-urban centers in Ethiopia, comes from these urban and peri-urban smallholder and commercial dairy producers $(10,11)$.

Despite the overall increased milk production, average milk yield per dairy cow remains low (1). In addition, fertility issues have been highlighted as a major problem in both local and crossbreed cattle in Ethiopia (12-14). Several factors contribute to this low productivity; among them diseases, nutrition, poor management, lack of infrastructure, and veterinary service provision $(15,16)$.

Longitudinal productivity studies are valuable tools to assess herd productivity, carry out cost-benefit analysis, evaluate potential health, and/or economic impacts of diseases and assess efficacy of interventions. These kind of studies provide a more accurate picture than rapid appraisals or cross-sectional studies. A longitudinal study on productivity of cattle held under traditional husbandry systems was performed in Ethiopia (17), which described herd dynamics, productivity parameters, and main constraints to better productivity. No such studies have so far been performed in the context of the Ethiopian urban dairy industry. Numerous research on dairy cattle productivity were done in Ethiopia but these either included small holders in periurban and rural areas, or focused only on a specific productivity parameter or are very much outdated $(13,14,18,19)$.

Current information on productivity in dairy cattle kept under intensive dairy systems in urban areas is lacking. The aims of this longitudinal study were to capture productivity parameters over a period of 3 years in selected intensive dairy farms in and around Addis Ababa (Central Ethiopia) and to assess some of the current challenges faced by farm owners for optimal animal performances.

\section{MATERIALS AND METHODS}

\section{Study Sites}

This study was carried out in Central Ethiopia within the greater milk production belt, namely Addis Ababa (Kaliti, Kolfe, Yeka, Gulele districts), as well as Debre Zeit (also known as Bishoftu) and Sendafa, 50 and $40 \mathrm{~km}$ away from the capital, respectively. Data were collected between November 2015 and September 2018. The area is conducive to dairy farming and has high production potential. It benefits from a temperate climate, abundant rainfall (1,000-1,900 mm/year) with good animal fodder potential and holds the largest high yielding dairy cow numbers in the country (1). The milk shed of the study areas has access to big markets including Addis Ababa (20).

\section{Study Farms and Animals}

This study was part of a larger study assessing Bovine tuberculosis (BTB) in dairy cattle in Central Ethiopia. A list of farms was obtained by district veterinary officers. For our study though, intensive urban dairy farms were purposively selected based on the willingness of the owners to collaborate on a 3-year longitudinal study. These owners were involved in the overall BTB testing program. Budget and logistics allowed for the selection of maximum 30 farms. Purposive sampling can lead to some degree of selection bias. Analysis of herd structure of the overall project in the area and of these selected farms were however very similar, hence giving evidence of representativity. Animals were high milk yielding Holstein-Friesian crossbreed cattle. Farm sizes were represented, and categorized into small farms (3-19 animals), medium farms (20-49 animals), and large farms (50 and more animals). Except for one government farm, all farms were privately owned. Husbandry was similar within farm size categories. Data from farms leaving the study for any reason before year 3 were not taken into account in the final data analysis.

Animals were categorized into sex and age class. Young stock were animals younger than 12 months, replacement stock were animals from 12 months to around 3 years, and breeders from 3 years onwards.

\section{Tools and Parameters Recorded}

An initial registration of all animals was performed in each farm at the start of the study. A herd-book was prepared capturing parameters such as any new animal entry (purchase, birth, gift), animal exit (selling, slaughtering, death), detailed data related to selling and purchasing of animals (e.g., cost, location, reason), morbidities including mastitis, mortalities, and fertility (AI dates, calving dates). The farms were visited twice a month by the same investigators. Herd-book information were updated on hard copies during each visit, and data entered in a Microsoft Access table. General observations were made on-farm during each visit (e.g., husbandry, fodder, discussion with farmers about any problems encountered). All animals were dewormed once a year with Albendazole by the farmers.

During the bi-monthly visits, the investigators who were all trained veterinarians offered advise on diverse husbandry issues and disease management, and provided training on particular topics on those farms that requested it (e.g., better heat detection, husbandry and fodder improvement, calf mortality, diseases).

\section{Data Analysis}

Data were entered into Microsoft Access, from which smaller subsets of data were transferred into Microsoft Excel tables to analyse particular parameters as needed. All data were analyzed using Stata 15 (StataCorp, Texas, USA). Data were analyzed using descriptive statistics. One-way analysis of variance (ANOVA) was used to analyze fertility parameters and results showed as Standard Error (SE), Standard Deviation (SD), 95\%CI, and $p$ value. Calving rates, mortality and morbidity rates, offtake rates, and sales rates were derived from the collected data. Offtake rates were the proportion of sold or slaughtered animals in one particular year. Net offtake rates were calculated as the number 
TABLE 1 | Overall cumulative herd structure categorized by sex and age class.

\begin{tabular}{lccc}
\hline Overall herd structure & Female & Male & Total \\
\hline Young stock (<1 year) & $481(36)$ & $333(90.5)$ & $814(47.7)$ \\
Replacement (1-3 years) & $313(23.4)$ & $23(6.2)$ & $336(19.7)$ \\
Breeder (>3 years) & $543(40.6)$ & $12(3.3)$ & $555(32.6)$ \\
\hline Total & 1,337 & 368 & 1,705 \\
\hline
\end{tabular}

of animals that were removed from the herd (slaughter/sold) minus the number of animals that were brought into the herd (purchase/gift) divided by the initial herd size (opening number) multiplied by 100 .

\section{Ethical Clearance}

This research study was approved by the Institutional Review Board (IRB) of Aklilu Lemma Institute of Pathobiology, Addis Ababa University (reference number IRB/ALIPB/2018), the Institutional Review Board of AHRI (AAERC) (reference number PO46/14), and supported by the Ethiopian Ministry of Livestock and Fisheries.

\section{RESULTS}

\section{Herd Structure and Dynamic}

Out of the 30 farms originally included in the study, six farms left either due to unwillingness to continue the study $(N=2)$, difficulty maintaining a herd-book follow-up (high staff rotation; poor data availability/accuracy) $(N=3)$ or due to farm closure $(N$ $=1)$. Data were collected from 24 dairy farms from November 2015 to September 2018 and included in the final data analysis. Eight farms were categorized as small with a mean herd size of 13.2 animals (95\%CI: 10.3-16.1) at initial registration. Eleven farms were medium sized with a mean herd size of 31 animals (95\%CI: 24.1-37.9). Five were large farms with a mean herd size of 93.8 animals (95\%CI: 65.5-122). A cumulative total of 1,705 animals were included in the study. The overall cumulative herd structure over the entire study duration is shown in Table 1. Female breeders accounted for $40.6 \%$ of all females. Of these, $10.9 \%$ were older than 10 years. Herd structure was similar in all three farm categories.

Overall, 789 new animals entered the study during the 3 years. The majority were calves born on farms $(724 ; 91.8 \%)$, whereas 49 (6.2\%) animals were purchased and $16(2 \%)$ were either shared between farms or given as gifts. Females represented $57.5 \%$ of all newborn calves. Heifers $(N=27)$ and cows $(N=13)$ represented the majority $(81.6 \%)$ of all purchased animals.

Overall, 830 animals left the study herds. The majority of exit were due to offtakes $(N=638 ; 76.6 \%)$ followed by natural death $(N=190 ; 23 \%)$, whereas $3(0.4 \%)$ animals were lost through divorce asset sharing and $1(0.1 \%)$ animal was stolen. Half of all exited animals (offtake and death) were calves $(N=417 ; 50.2 \%)$, a third were adult breeders $(N=281 ; 33.9 \%)$, and the others replacements $(N=132 ; 15.9 \%)$.
Half of the farms (50\%) saw their animal numbers increase over the 3 years (total herd increase by $42 \%), 3$ (12.5\%) remained stable whereas 9 farms (37.5\%) saw their animal numbers decrease (total herd decrease by $30.6 \%$ ), including 4 out of the 5 large farms $(80 \%)$. Geographical location $(p=0.33)$ and farm size $(p=0.163)$ were not statistically associated with change in herd size.

\section{Offtakes and Natural Death}

During the study, 190 (11.1\%) animals died of natural causes. Table 2 shows the mortality and offtakes by age and sex during the entire study.

The highest mortality was observed in young stock (13.9\%), where mortality in males (15\%) was higher than in females (13.1\%).

The cause of death was known for 134 animals (see Figure 1). Overall, infectious diseases were the leading cause of animal mortality.

Among the 39 calves for which detailed information on the cause of death existed, besides infectious diseases, diarrhea accounted for the highest mortality $(N=17 ; 43.6 \%)$. Unexplained progressive weakness, emaciation, and refusal to drink caused death in 10 calves $(25.7 \%), 5$ (12.8\%) died at birth, $4(10.2 \%)$ animals died of respiratory distress, 2 of bone deformation/lameness, 1 had swallowed a foreign body and choked, another 3 died suddenly.

The majority ( $N=78 ; 69 \%)$ of all calves died during their first week of life, whereas $87.6 \%(N=99)$ died before the age of 6 months.

Among breeders, a third (34\%) of the deaths were caused by digestive problems including metabolic problems, $25 \%$ were caused by parturition related problems and another $25 \%$ by infectious diseases [rabies, Foot- and Mouth Disease (FMD), and Bovine Viral Diarrhea (BVD)]. Hypocalcaemia (milk fever) was the cause of $13.6 \%$ of all female breeder's death. Another $13.6 \%$ died after experiencing progressive emaciation and weakness.

Table 3 shows the crude offtake rates (COR) and the net offtake rates (NOR) per age group and sex for year 1 and year 2 . Year 3 was an incomplete 12 months period and hence data were not used in this table. The biggest offtake rates were observed in male calves $(\mathrm{NOR}=70.6 \%)$. The majority of male calf offtakes happened in the first month of life (81.6\%). A 185 (77.4\%) calves were removed from the herd between the age of one and 15 days. Nineteen (79\%) female calves were removed when aged 5 months or older.

\section{Morbidity}

Overall, 297 animals were reported sick during the study. Infectious diseases (33.7\%), leg problems (lameness, arthritis, wounds, edema, abscess) (19.9\%), and diarrhea (13.1\%) were the three most recorded problem categories, followed by fertility/genital tract related problems $(7.4 \%)$, respiratory $(2.7 \%)$, and others (23.2\%).

Detailed information on morbidity was recorded in 225 replacement/breeders and 63 young stock (see Figures 2A,B).

In replacements and breeders, the leading causes of morbidity were known infectious diseases $(N=$ 
TABLE 2 | Mortality and offtake numbers by age and sex during the entire study period.

\begin{tabular}{|c|c|c|c|c|c|}
\hline Age and sex category & $\begin{array}{l}\text { Total cumulative } \\
\text { numbers }\end{array}$ & \multicolumn{2}{|c|}{ Natural death } & \multicolumn{2}{|c|}{ Offtakes } \\
\hline Young stock & 814 & 113 & 13.9 & 263 & 32.3 \\
\hline Female & 481 & 63 & 13.1 & 24 & 4.9 \\
\hline Male & 333 & 50 & 15 & 239 & 71.7 \\
\hline Female & 238 & 15 & 6.3 & 38 & 15.9 \\
\hline Male & 35 & 2 & 5.7 & 15 & 42.8 \\
\hline Breeder & 657 & 60 & 9.1 & 323 & 49.1 \\
\hline Female & 645 & 60 & 9.3 & 320 & 49.6 \\
\hline Male & 12 & 0 & 0 & 3 & 25 \\
\hline
\end{tabular}

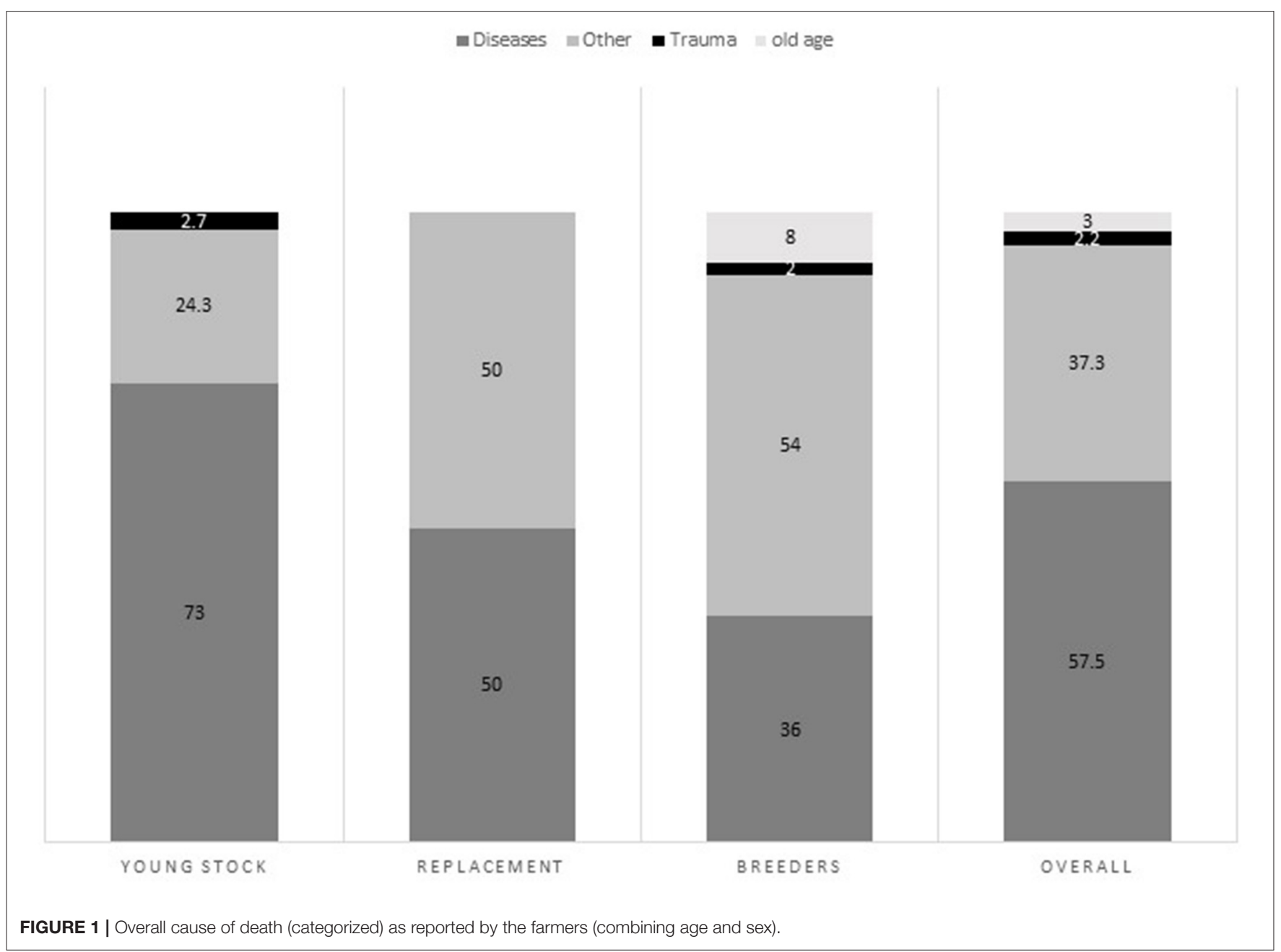

58; 25.8\%) such as BVD, FMD, Lumpy skin disease (LSD), and rabies. Skin diseases ranked second with 40 cases (17.7\%), followed by musculoskeletal problems (16.4\%).
In addition, clinical mastitis was recorded in 76 animals (heifers and breeders), which accounts for approximately $9 \%$ morbidity. This number is likely severely underestimating the true mastitis incidence (personal observation). 


\section{A}

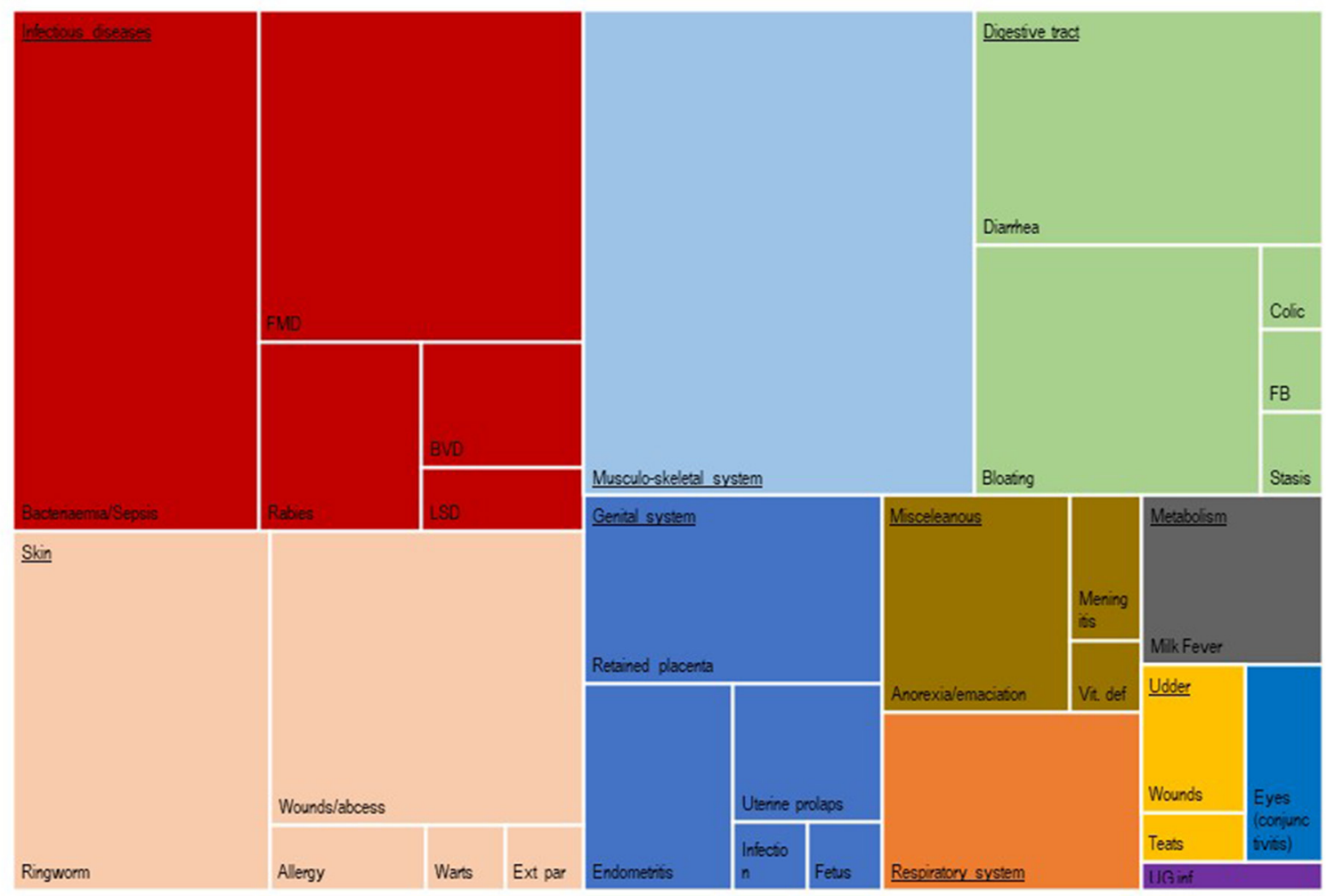

B

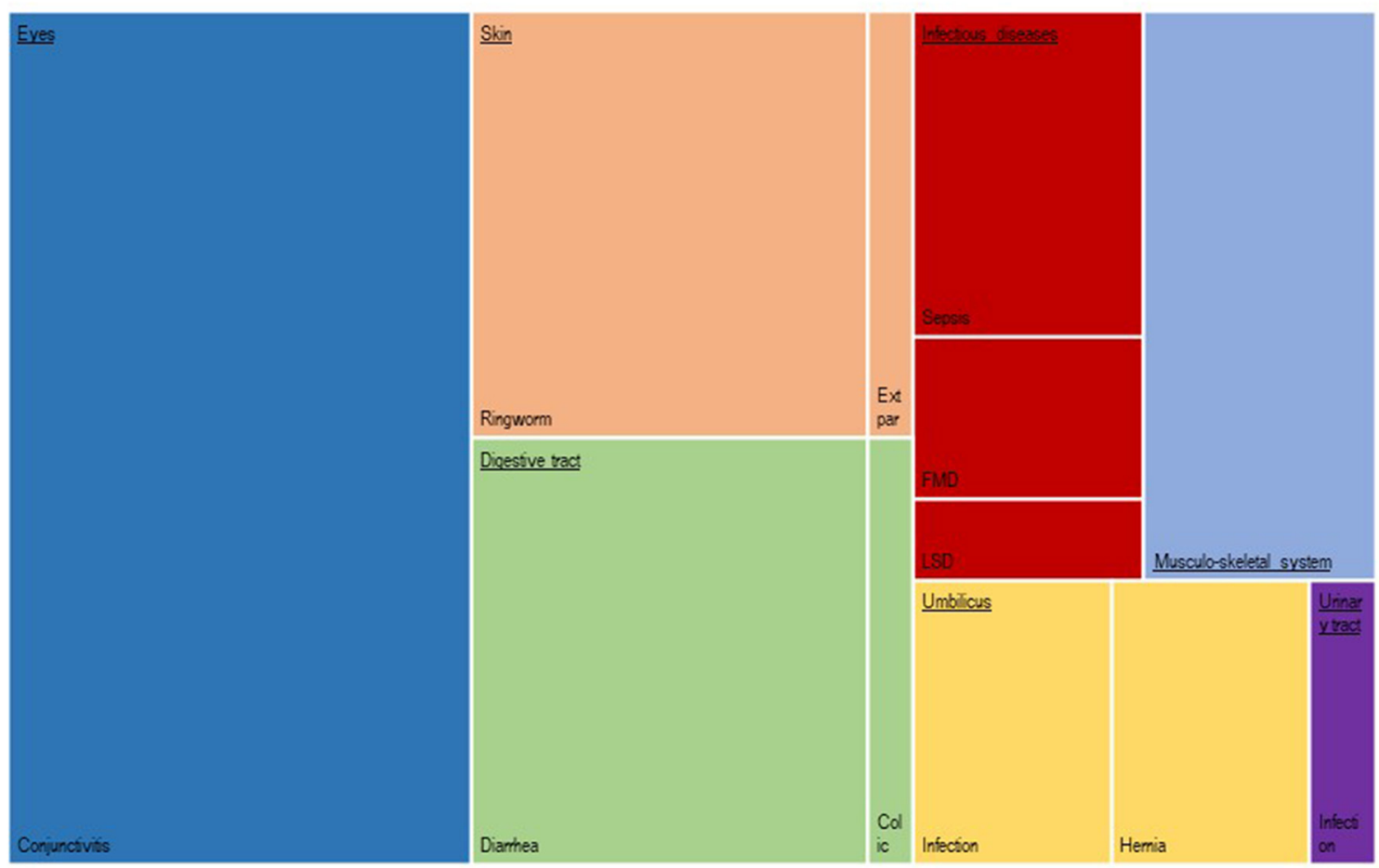

FIGURE 2 | Detailed health problems as recorded in 288 animals (A in 225 replacement/breeder animals; B in 63 young stock). 
TABLE 3 | Crude offtake rates (COR) and Net offtake rates (NOR) by age and gender for the first and second year of the study.

\begin{tabular}{|c|c|c|c|c|c|c|c|c|c|c|c|c|}
\hline \multirow[b]{2}{*}{ Age } & \multicolumn{2}{|c|}{ Number animals } & \multicolumn{2}{|c|}{ Number offtakes } & \multicolumn{2}{|c|}{ Number purchases } & \multirow{2}{*}{$\frac{\text { COR (\%) }}{\text { Year } 1}$} & \multirow[b]{2}{*}{ Year 2} & \multirow{2}{*}{$\frac{\text { NOR (\%) }}{\text { Year } 1}$} & \multirow[b]{2}{*}{ Year 2} & \multirow[b]{2}{*}{$\begin{array}{l}\text { Average } \\
\text { COR (\%) }\end{array}$} & \multirow[b]{2}{*}{$\begin{array}{l}\text { Average } \\
\text { NOR (\%) }\end{array}$} \\
\hline & Year 1 & Year 2 & Year 1 & Year 2 & Year 1 & Year 2 & & & & & & \\
\hline Young stock & 365 & 457 & 137 & 115 & 0 & 2 & 37.5 & 25.1 & 37.5 & 24.7 & 31.3 & 31.1 \\
\hline Female & 230 & 316 & 38 & 18 & 0 & 1 & 16.5 & 5.7 & 16.5 & 5.4 & 11.1 & 10.9 \\
\hline Male & 135 & 141 & 99 & 97 & 0 & 1 & 73.3 & 68.8 & 73.3 & 68 & 71 & 70.6 \\
\hline Replacement & 308 & 273 & 112 & 71 & 11 & 21 & 36.4 & 26 & 32.8 & 18.3 & 31.2 & 25.5 \\
\hline Female & 289 & 255 & 110 & 71 & 9 & 20 & 38 & 27.8 & 35 & 20 & 32.9 & 27.5 \\
\hline Male & 19 & 18 & 2 & 0 & 2 & 1 & 10.5 & 0 & 0 & & 5.2 & 0 \\
\hline Breeder & 538 & 433 & 240 & 143 & 49 & 48 & 44.6 & 33 & 35.5 & 21.9 & 38.8 & 28.7 \\
\hline Female & 528 & 422 & 219 & 140 & 47 & 45 & 41.5 & 33.2 & 32.6 & 22.5 & 37.3 & 27.5 \\
\hline Male & 10 & 11 & 3 & 3 & 2 & 3 & 30 & 27.3 & 10 & 0 & 28.6 & 5 \\
\hline Total & 1,211 & 1,163 & 471 & 329 & 60 & 71 & 38.9 & 28.3 & 33.9 & 22.2 & 33.6 & 28 \\
\hline
\end{tabular}

\section{Fertility}

Table 4 shows the results for four fertility parameters for each farm size category. Generally, larger farms tended to show better performances with a clear statistical difference $(p=0.007)$ for calving to next service interval as compared with the other farms.

Forty-six animals out of 870 animals that had received at least one artificial insemination (AI) had aborted (5.3\%).

Out of 610 animals that received AI, 341 had calved successfully (55.9\%), whereas 175 failed to calve after 9 months (28.7\%). Ninety-four were slaughtered or sold before the end of the 9 month pregnancy period (15.4\%).

Overall, one-third of the AI did not lead to a successful calving. The conception rate decreased as the farm size decreased, and was lower in Addis Ababa as compared to the other geographical locations (see Table 5).

The numbers of AI provided per animal ranged from one to ten, with a median (50th percentile) of one (Table 6). Indeed, the majority of animals (65.4\%) only had one AI; $83.9 \%$ received one or two; $14.2 \%$ received between three and five; and $1.9 \%$ received six or more AIs (Table 6).

\section{DISCUSSION}

Knowledge of herd structure, fertility, mortality, and offtake rates are key parameters for determining the population dynamics and herd productivity in the dairy sector at both farm and country level.

Long-term longitudinal studies have pros and cons. There is always the risk of participation bias, drop-outs during the study and delayed data analysis and results. They require a substantial time effort, which is also often linked to logistical and financial challenges and limitations. However, these type of studies produce more accurate and reliable data, reduce recall biases and are closer to the reality of event timelines, allowing to assess cause-effects more accurately. Representativeness of the larger population is always a limitation. In our study, we compared herd structure and farm size with the ones provided by the larger project for Central Ethiopia and they were very similar, thus providing some indication of representativeness. However, results translation to the larger national dairy cattle population should be done with care.

Major challenges faced in our study to record productivity were: lack of animal identification, lack of record keeping, high staff turn-over, lack of interest of owners, and depopulation or closing down of farms. Only a few farms (including all large farms) had their animals officially tagged despite the Ethiopian Government's efforts to implement a livestock identification system using plastic ear tags through the National Artificial Insemination Center (NAIC). The Ethiopian Ministry of Livestock and Fisheries launched a national livestock identification and traceability system (LITS) with the financial and technical support of the U.S. Agency for International Development (USAID) (21). Unfortunately, the system was not fully implemented during the time of our study. Owners would rely on their own identification system (individual name; own ear tag number) that were sometimes replaced entirely after some time with other ear tag numbers. Re-using ID tags of existing animals for a new animal was common. Accurate and updated record keeping of animals and productivity parameters were performed only in two large farms ( $8.3 \%$ of the farms). Two other large farms kept records on animal identification and some basic animal data but rarely updated the information on productivity. Hence the need for the study to introduce an independent animal registration and herd book that could be followed up for 3 years. In addition, dairy farm staff in medium and large farms were often untrained and showed high work turn-over. This likely contributed to poor animal management in many of the dairy farms. Nine farms (37.5\%), including 4 out of the 5 large farms, decreased their number of animals. Reasons given included diseases, high running costs, poor availability of fodder, and poor animal productivity.

Dairy farms kept mainly female animals (78.4\%). Among the males, the great majority were young calves $(90.5 \%)$. Male calves represented also the biggest offtake (70.6\%). They were largely removed from the farm during the first month of life, with $81.6 \%$ removed within the first 14 days of life. Currently 
TABLE 4 | Fertility parameters during the study period.

\begin{tabular}{|c|c|c|c|c|c|c|c|}
\hline Parameter & Farm size & Total number & Mean days & SE & $\mathrm{Cl}$ for mean (days) & Min-Max (days) & $P$-value \\
\hline \multirow{3}{*}{ DOB to first calving } & Small & 6 & 785 & 37.9 & $687.7-882.3$ & 691-950 & 0.125 \\
\hline & Medium & 14 & 740.1 & 32.1 & $670.7-809.5$ & $617-1,044$ & \\
\hline & Overall & 39 & 794.7 & 24.5 & $744.9-844.4$ & $455-1,144$ & \\
\hline \multirow[t]{2}{*}{ DOB to first service } & Small & 10 & 592.2 & 14.7 & $563.1-621.4$ & $422-675$ & 0.175 \\
\hline & Overall & 86 & 592.2 & 14.7 & $563.1-621.4$ & $380-967$ & \\
\hline \multirow[t]{4}{*}{ Calving to next service } & Small & 54 & 168.5 & 11.7 & $144.9-192$ & $55-436$ & 0.007 \\
\hline & Medium & 84 & 158 & 11.8 & $134.6-181.5$ & $21-669$ & \\
\hline & Large & 255 & 146.6 & 5.1 & $136.5-156.8$ & $4-659$ & \\
\hline & Overall & 393 & 152 & 4.5 & $143.2-160.9$ & $4-669$ & \\
\hline Calving interval & overall & 288 & 483.2 & 8.4 & $466.7-499.7$ & 272-967 & \\
\hline
\end{tabular}

$D O B$, date of birth.

TABLE 5 | Number of successful Als by farm size category and geographical locations.

\begin{tabular}{lllcc}
\hline Category & Total Al & $\begin{array}{c}\text { Total failed conception } \\
\text { after Al (\%) }\end{array}$ & $\begin{array}{c}\text { Total successful } \\
\text { conception after Al (\%) }\end{array}$ & $\begin{array}{c}\text { Anova Bartlett's test } \\
\boldsymbol{p} \text {-value }\end{array}$ \\
\hline Farm size & Small (3-19) & 56 & $28(50)$ & $28(50)$ \\
& Medium (20-49) & 147 & $62(42.2)$ & $85(57.8)$ \\
& Large (50+) & 313 & $85(27.1)$ & $228(72.8)$ \\
Location & Addis & 257 & $112(43.6)$ & $145(56.4)$ \\
& Debre Zeit & 136 & $35(25.7)$ & $101(74.3)$ \\
& Sendafa & 123 & $123(22.8)$ & $95(77.2)$ \\
\hline Total & 516 & $175(33.9)$ & $341(66.1)$
\end{tabular}

TABLE 6 | Number of artificial insemination given per cow by farm-size category.

\begin{tabular}{lcccc}
\hline Number of Al/cow & Small farm & Medium farm & Large farm & Total \\
\hline 1 & $57(58.8)$ & $163(72.8)$ & $337(63.5)$ & $557(65.4)$ \\
2 & $19(19.6)$ & $38(17)$ & $101(19)$ & $158(18.5)$ \\
$3-5$ & $17(17.5)$ & $22(9.8)$ & $82(15.4)$ & $121(14.2)$ \\
$\geq 6$ & $4(4.1)$ & $1(0.4)$ & $11(2)$ & $16(1.9)$ \\
\hline Total & 97 & 224 & 531 & 852
\end{tabular}

not much veal meat is produced; it comes from very young calves (younger than 1 month old) with a market directed mainly to expatriate communities living in the capital city. Offtakes represented the majority of all animal exits, whereas natural death accounted for a quarter of the exits. Farms relied predominantly on own breeding rather than purchasing new animals $(N=49 ; 6.2 \%)$. Low numbers of purchased animals are ideal from a biosecurity point of view as the additional risk and burden of importing new diseases into the farm remains low at farm level.

Highest mortality was found among young stock (13.9\%), which is higher than calf mortality of $9.3 \%$ found in small-holders in Hawassa (22) but in line with results found in calves from dairy farms by Romha et al. (23) in Debre Zeit (Bishoftu). The latter study observed that lack of colostrum provision was the major cause of mortality and diarrhea in calves. In our study, we did not follow up on the provision of colostrum. However, diarrhea accounted for $43.6 \%$ of calf mortality suggesting husbandry issues. Diarrhea was also observed by Megersa et al. (22) to be the leading cause of calf morbidity. A quarter of calves (25.7\%) died following a period of progressive emaciation and reluctance to take milk, also suggestive of possible husbandry problems. Farmers acknowledged that calf mortality was one of the major issues on their farm in addition to fertility problems. Mortality in male calves (15\%) was a slightly higher than in female calves (13.9\%). This might reflect the fact that male calves were removed mostly within the first 2 weeks of life and were thus neglected. Death during birth or shortly after birth was 
recorded in $12.8 \%$ of calves. High neonatal calf mortality was also observed in dairy farms by Fentie et al. (24). High calf mortality was one of the major complaints of the farm owners in our study. Among breeders, a quarter (25\%) died due to parturition problems (e.g., birthing, endometritis, uterine prolapse). These results highlighted poor obstetric practices and husbandry as well as poor nutritional management (25). A third of all deaths in adults were caused by digestive/metabolic problems hinting again to poor husbandry and feeding practices. Milk fever is a metabolic disease caused by blood calcium deficiency around birth time, leading to poor labor activity (dystocia), birth of weak calves or stillborn, and can be fatal for cows. In our study, $13.6 \%$ of breeders who died had milk fever. Gammada (26) also observed $17.3 \%$ of milk fever cases in small-scale dairy farms in Jimma. Hypocalcaemia, which was probably under-reported, could also be a cause for the high level of parturition issues and high calf mortality at birth. The condition is more prevalent in pluriparous cows with higher milk production, and is strongly linked to feeding management during the weeks prior to calving. A previous study by GebreMichael et al. (9) showed that $70 \%$ of the study farms did not adapt the diet of their pregnant cows during the critical dry period.

Husbandry and fodder issues were reflected in several of the reported animal morbidities. Leg problems involving arthritis, wounds, and abscesses were reported in $19.9 \%$ of the animals. In addition, not recorded but observed by the researchers was the high prevalence of untrimmed hooves in all farms, leading to chronic hoof deformities and lameness. Chronic pains and inability to walk, jump, and display normal behavior can have an impact on fertility (poor heat detection) but also on milk productivity (27). The many metabolic issues reported such as bloating and milk fever are indications of inadequate fodder intake and feeding management. Anecdotally, some farmers were observed giving colostrum to drink to cows that had calved, leading to serious bloating. Infectious diseases were the top causes for animal morbidity (33.7\%). Infectious diseases, such as Blackleg and LSD were also previously observed being leading causes of morbidities in small-scale dairy farms in Jimma (26). In our study, Besides bacterial septicemia, FMD, LSD, and BVD were recorded. Foot- and mouth disease is an endemic disease in Ethiopia with sero-prevalence in Central Ethiopia ranging between 14.5 and 30\% (28-30). Lumpy skin disease prevalence in dairy cattle in Central Ethiopia ranges from 22.5 to $33.9 \%$ with mortality up to $7.4 \%(31,32)$. Seropositivity of BVD was reported in dairy cattle as high as $32.6 \%$ (33). Infectious diseases can have a range of impacts on animal productivity. In our study, none of the farms had consistent appropriate biosecurity measures in place. The reasons were not specifically investigated as part of the study but included lack of awareness and cost. Infectious diseases were also the leading cause of death. In adults, rabies, FMD and BVD caused $25 \%$ of all deaths during the study period. LSD and FMD vaccines are produced incountry, though sometimes with limited capacity. Most farmers do not regularly vaccinate their cattle and rather wait for an outbreak to do so often worsening the outbreak situation and increasing complaints from farmers about the vaccine efficacy (NVI, personal communication).
Mean calving interval (CI) in our study was 483.2 days (16 months). This is a sub-optimal CI as compared to the ideal 365 days for dairy cattle (34). Studies on reproductive performances in intensive dairy cows in Ethiopia are sparse or outdated (35). Twenty years ago, studies done in dairy cattle in Central Ethiopia showed a CI ranging between 435.2 and 544.9 days (average 490 days) (18), which indicates the fertility performances have not much improved. Several factors can contribute to this long CI. Lobago et al. (19) showed that $67.4 \%$ of cows showed a delayed return to ovarian cyclicity after calving (longer than 55 days). Prolonged postpartum anestrus is most likely linked to inadequate nutrient intake. Other factors influencing the CI include the ideal timing of post breeding pregnancy testing (36) and proper service. In our study the majority of cows $(65.4 \%)$ received only one AI. Besides financial constraints, this was mostly due to the lack of qualified insemination technicians or technicians not coming to the farm after the call and thus missing the estrus period. On the other hand, some animals in large farms received up to 10 AIs. Large farms sometimes have assigned AI technicians who are on call. The mean time between calving and the first AI given was 152 days (CI: 143.2-160.9). This was longer than the reported 115 days by Tadesse et al. (35) and much longer than the ideal calving-first insemination interval. Intervals between two AIs without a calf being produced ranged between 1 and 408 days. The median interval was 59.5 days (CI: 49.166 days). Animals were sometimes inseminated although not showing signs of estrus, e.g., during the first couple of weeks after calving (7.2\% of AIs), during pregnancy, or the AI technician inseminated several animals the same day to reduce the numbers of visits even if outside the possible estrus period. $40.5 \%$ of AIs were repeated after 2.5 months. Poor estrus expression, detection by the owner, and poor AI techniques (timing, conception rate, pregnancy diagnosis, etc.), led to poor service per conception outputs. Infectious diseases are also known to affect fertility and cause diverse reproductive disorders. In intensive dairy cattle in central Ethiopia, high prevalence of Neospora caninum and Schmallenberg virus were both observed (37-39), whereas BVD was linked in Jimma (Western Ethiopia) with reproductive disorders in cattle (40).

Overall, $28.7 \%$ of all inseminations failed to conceive a calf after 9 months. The conception rate was better the bigger the farm. Small farms fared the worst as well as Addis Ababa (56.4\%) as compared to the other sites. Abortion rate was in our study $5.3 \%$. Previously reported abortion rates ranged between 1.7 and $20.2 \%(18,41)$.

Our study showed overall sub-optimal productivity performances in intensive dairy farms, likely contributing to substantial financial losses at farm level. Keeping accurate herd book follow-up data would help identifying correctly and swiftly animals with reproductive problems, hence would help improve farm productivity. Record keeping helps managing the question of profitability to continue to inseminate animals with problems and this will increase farm profit. The problems highlighted in this study are complex and often interlinked. A holistic approach is needed in order to improve overall animal productivity. Poor husbandry was observed to be a major contributor to poor productivity, affecting among others calf 
mortality, and animal fertility. These were also the two major topics that farmers would regularly raise during our entire study and questioning how to address them.

\section{CONCLUSION}

Longitudinal productivity studies and herd-book follow-ups are great tools to identify productivity challenges and establish baseline productivity data, on which further economic studies can be built upon. Despite the growing importance of the dairy industry in Ethiopia, accurate data on dairy cattle productivity under intensive farming is often lacking. Larger sample size would be warranted to corroborate our findings. Besides improving animal tracking (ear-tagging that is reliable and centralized), keeping accurate animal records and tackling prevalent infectious diseases, emphasis should be urgently given to improving overall animal husbandry and feeding, all of which would ultimately lead to better productivity and better animal welfare. Continuous training opportunities of farmers and their staff is a key step toward improving all the above mentioned aspects. Certifications of farms, and creation of model-farms can further help improve training quality and standard, and provide a positive deviance approach to better animal husbandry.

\section{THE ETHICOBOTS CONSORTIUM}

The members of the Ethiopia Control of Bovine Tuberculosis Strategies (ETHICOBOTS) consortium are: Abraham Aseffa, Adane Mihret, Bamlak Tessema, Bizuneh Belachew, Eshcolewyene Fekadu, Fantanesh Melese, Gizachew Gemechu, Hawult Taye, Rea Tschopp, Shewit Haile, Sosina Ayalew, Tsegaye Hailu, Armauer Hansen Research Institute, Ethiopia; Rea Tschopp from Swiss Tropical and Public Health Institute, Switzerland; Adam Bekele, Chilot Yirga, Mulualem Ambaw, Tadele Mamo, Tesfaye Solomon, Ethiopian Institute of Agricultural Research, Ethiopia; Tilaye Teklewold from Amhara Regional Agricultural Research Institute, Ethiopia; Solomon Gebre, Getachew Gari, Mesfin Sahle, Abde Aliy, Abebe Olani, Asegedech Sirak, Gizat Almaw, Getnet Mekonnen, Mekdes Tamiru, Sintayehu Guta, National Animal Health Diagnostic and Investigation Center, Ethiopia; James Wood, Andrew Conlan, Alan Clarke, Cambridge University, United Kingdom; Henrietta L. Moore and Catherine Hodge, both from University College London, United Kingdom; Constance Smith at University of Manchester, United Kingdom; R. Glyn Hewinson, Stefan Berg, Martin Vordermeier, Javier Nunez-Garcia, Animal and Plant Health Agency, United Kingdom; Gobena Ameni, Berecha

\section{REFERENCES}

1. CSA. Agricultural Sample Survey 2017/18, Report on Livestock and Livestock Characteristics. Volume II:Statistical Bulletin 587. Addis Ababa: Central Statistical Agency (2018).

2. Yilma Z, Guernebleich E, Sebsibe A, Fombad R. A Review of the Ethiopian Dairy Sector. Addis Ababa: FAO Sub Regional Office for Eastern Africa (FAO/SFE). (2011)
Bayissa, Aboma Zewude, Adane Worku, Lemma Terfassa, Mahlet Chanyalew, Temesgen Mohammed, Miserach Zeleke, Addis ababa University, Ethiopia.

\section{DATA AVAILABILITY STATEMENT}

The datasets presented in this article are not readily available because Project regulations of the Ethicobots consortium project (PI: JW). Requests to access the datasets should be directed to JW (jlnw2@cam.ac.uk).

\section{ETHICS STATEMENT}

This research study was approved by the Institutional Review Board (IRB) of Aklilu Lemma Institute of Pathobiology, Addis Ababa University (reference number IRB/ALIPB/2018), the Institutional Review Board of AHRI (AAERC) (reference number PO46/14), and supported by the Ethiopian Ministry of Livestock and Fisheries. Written informed consent for participation was not obtained from the owners because a verbal informed consent was provided by the participants.

\section{AUTHOR CONTRIBUTIONS}

RT has designed the research, performed the data analysis, and drafted the manuscript. GG has collected field data and contributed to drafting the manuscript. JW provided critical comments to the Manuscript. All authors have contributed to the manuscript, and have approved the submitted version.

\section{FUNDING}

This work was funded by the Biotechnology and Biological Sciences Research Council, the Department for International Development, the Economic and Social Research Council, the Medical Research Council, the Natural Environment Research Council, and the Defense Science and Technology Laboratory, under the Zoonoses and Emerging Livestock Systems (ZELS) programme, ref.: BB/L018977/1. The funders did not involve in the design of the study and collection, analysis, and interpretation of data and in writing the manuscript.

\section{ACKNOWLEDGMENTS}

We thank AHRI for its logistic support. A warm thank you goes to Jakob Zinsstag, Solomon Araya GebreMichael, and to all farm owners for their willingness to cooperate in this study. 
5. Ahmed MA, Ehui S, Assefa Y. Dairy Development in Ethiopia. EPTD Discussion Paper 123. Washington, DC: International Food Policy Research Institute (IFPRI) (2004).

6. Mekonnen GA, Ameni G, Wood, JLN, The ETHICOBOTS Consortium, Berg S, Conlan AJK. Network analysis of dairy cattle movement and associations with bovine tuberculosis spread and control in emerging dairy belts of Ethiopia. BMC Vet Res. (2019) 15:262. doi: 10.1186/s12917-019-1962-1

7. Mekonnen GA, Conlan AJK, Berg S, Ayele BT, Mihret A, Olani A, et al. Dynamics and risk of transmission of bovine tuberculosis in the emerging dairy regions of Ethiopia. Epidemiol Infect. (2021) 149:e69. doi: 10.1017/S0950268821000480

8. Staal S. The Economic Impact of Public Policy on Smallholder Peri-urban Dairy Producer in and around Addis Ababa, Ethiopia. Publication No 2. Addis Ababa: Society of Animal Production (ESAP) (1996).

9. GebreMichael S, Gemete G, Mihret A, Waelti P, Tschopp R. Socioeconomic aspects related to feeding resources and practices in selected intensive dairy farms in Central Ethiopia. AJAR. (2019) 14:252-62. doi: 10.5897/AJAR2018.13156

10. Tegegne, A., and Gebre-Wold, A. (1998). Prospects for peri-urban dairy development in Ethiopia. In: Proceedings of the $5^{\text {th }}$ National Conference of Ethiopian Society of Animal Production. Addis Ababa: Ethiopian Society of Animal Production (1997) p. 28-39.

11. Zijlstra J, Berhanu T, Vernooij A, Van der Lee J. Investment opportunities in the Ethiopian Dairy sector. In: Business Opportunities Report Dairy \#2 in the series written for the Ethiopian Netherlands Business Event 5-6 November. Rijswijk (2015).

12. Shiferaw Y, Tenhagen BA, Bekana M, Kassa T. Reproductive disorders of crossbred dairy cows in the central highlands of ethiopia and their effect on reproductive performance. Trop Anim Health Prod. (2005) 37:42741. doi: 10.1007/s11250-005-7050-5

13. Duguma B, Kechero Y, Yanssens GPJ. Productive and reproductive performance of zebu x Holstein-Friesian crossbred dairy cows in Jimma town, Oromia, Ethiopia. Glob Vet. (2012) 8:67-72.

14. Dinka H. Major reproductive diseases of dairy cows in and around Asella town, Central Ethiopia. J Vet Med Anim Health. (2013) 5:1137. doi: 10.5897/JVMAH2013.0197

15. Yoseph, M. (1999). Impact of Feed Resources on Productive and Reproductive Performance of Dairy Cows in the Peri-Urban Dairy Production Systems in the Addis Ababa Milk Shed and Evaluation of Non-Conventional Feed Resources Using Sheep. MSc thesis, Alemaya University of Agriculture, Dire Dawa, Ethiopia.

16. Getabalew M, Alemneh $\mathrm{T}$, Akeberegn D. Dairy production in ethiopia - existing scenario and constraints. Biomed J Sci Tech Res. (2019) 16:12304-9. doi: 10.26717/BJSTR.2019.16.00 2903

17. Tschopp R, Aseffa A, Zinsstag J. Cattle productivity under traditional village husbandry system in Sellale, Central Ethiopia: a four and a half year herd follow-up. Int J Agric Innov Res. (2014) 2:723-31.

18. Bekele T, Kasali OB, Alemu T. Reproductive problems in crossbred cattle in central Ethiopia. Anim Reprod Sci. (1991) 26:41-9. doi: 10.1016/0378-4320(91)90064-7

19. Lobago F, Bekana M, Gustafsson H, Kindahl H. Longitudinal observation on reproductive and lactation performances of smallholder crossbred dairy cattle in Fitche, Oromia region, central Ethiopia. Trop Anim Health Prod. (2007) 39:395-403. doi: 10.1007/s11250-007-9027-z

20. Fransesconi GN, Ruben R. The hidden impact of cooperative membership on quality management: a case study from the dairy belt of Addis Ababa. $J$ Entrepren Organ Divers. (2012) 1:85-103. doi: 10.5947/jeod.2012.005

21. ILRI. (2014). Livestock identification and traceability systems in the Intergovernmental Authority on Development (IGAD) region. In: Proceedings of a Regional Workshop, Addis Ababa, Ethiopia, 4-5 February. Nairobi: International Livestock Research Institute (ILRI).

22. Megersa B, Yacob A, Regassa A, Abuna F, Asmare K, Amenu K. Prevalence and incidence rates of calf morbidity and mortality and associated risk factors in smallholder dairy farms in Hawassa, Southern Ethiopia. Ethiop Vet J. (2009) 13:59-68.
23. Romha G. Major causes of calf mortality in intensive dairy farms, central ethiopia - a cohort study. Int J Livestock Res. (2014) 4:9-16. doi: 10.5455/ijlr.201404210 93417

24. Fentie T, Guta S, Mekonen G, Temesgen W, Melaku A, Asefa G, et al. Assessment of major causes of calf mortality in urban and periurban dairy production system of Ethiopia. Vet Med Int. (2021). 2021:3075429. doi: 10.1155/2020/30 75429

25. Roche JF. The effect of nutritional management of the dairy cow on reproductive efficiency. Anim Reprod Sci. (2006) 96:282-96. doi: 10.1016/j.anireprosci.2006. 08.007

26. Gammada I. Assessment on economic losses due to animal health and production. Constraints in Jimma town intensive dairy farms, Jimma, Ethiopia. Eur J Med Health Sci. (2020) 2:52-60. doi: 10.34104/ejmhs.020. 052060

27. Huxley JN. Impact of lameness and claw lesions in cows on health and production. Livest Sci. (2013) 156:64-70. doi: 10.1016/j.livsci.2013. 06.012

28. Ayalet G, Gelaye E, Negussie H, Asmare K. Study on the epidemiology of foot and mouth disease in Ethiopia. Rev Sci Tech. (2012) 31:789-98. doi: 10.20506/rst.31. 3.2153

29. Alemayehu G, Zewde G, Admassu A. Seroprevalence of foot and mouth disease (FMD) and associated economic impact on Central Ethiopian cattle feedlots. J Vet Med Anim Health. (2014) 6:154-8. doi: 10.5897/JVMAH2013. 0247

30. Sulayeman M, Dawo F, Mammo B, Gizaw D, Shegu D. Isolation, molecular characterization and sero-prevalence study of foot-and-mouth disease virus circulating in central Ethiopia. BMC Vet Res. (2018) 14:110. doi: 10.1186/s12917-018-1 429-9

31. Ayalet G, Abate Y, Sisay T, Nigussie H, Gelaye E, Jemberie S, et al. Lumpy skin disease: preliminary vaccine efficacy assessment and overview on outbreak impact in dairy cattle at Debre Zeit, central Ethiopia. Antiviral Res. (2013) 98:261-5. doi: 10.1016/j.antiviral.2013. 02.008

32. Garie G, Bonnet P, Roger F, Waret-Skuta A. Epidemiological aspects and financial impact of lumpy skin disease in Ethiopia. Prev Vet Med. (2011) 102:274-83. doi: 10.1016/j.prevetmed.2011 07.003

33. Aragaw K, Sibhat B, Ayelet G, Skjerve E, Gebremedhin EZ, Asmare K. Seroprevalence and factors associated with bovine viral diarrhea virus (BVDV) infection in dairy cattle in three milksheds in Ethiopia. Trop Anim Health Prod. (2019) 50:1821-7. doi: 10.1007/s11250-018-1 624-5

34. Do C, Wasana N, Cho K, Cho K, Choi Y, Choi T, et al. The effect of age at first calving and calving interval on productive life and lifetime profit in Korean holsteins. Asian Aust J Anim Sci. (2013) 26:1511-7. doi: 10.5713/ajas.2013. 13105

35. Tadesse M, Thiengtham J, Pinyopummin A, Prasanpanich S. Productive and reproductive performance of Holstein Friesian dairy cows in Ethiopia. Livestock Res Rural Dev. (2010) 22:20.

36. White ME, LaFaunce N, Mohammed HO. Optimal time post breeding for pregnancy examination in dairy cattle. Canad Vet J. (1989) 3:147-9.

37. Asmare K, Regassa FG, Robertson LJ, Martin AD, Skjerve E. Reproductive disorders in relation to Neospora caninum, Brucella spp. and bovine viral diarrhoea virus serostatus in breeding and dairy farms of central and southern Ethiopia. Epidemiol Infect. (2012) 141:1-9. doi: 10.1017/S0950268812 002191

38. Sibhat B, Ayelet G, Gebrenedhin EZ, Skjerve E, Asmare K. Seroprevalence of Schmallenberg virus in dairy cattle in Ethiopia. Acta Trop. (2018) 178:617. doi: 10.1016/j.actatropica.2017.10.024

39. Tulu D, Deresa B, Begna F, Gojam A. Review of common causes of abortion in dairy cattle in Ethiopia. $J$ Vet Med 
Anim Health. (2018) 10:1-13. doi: 10.5897/JVMAH2017. 0639

40. Tadesse T, Deneke Y, Deresa B. Seroprevalence of bovine viral diarrhea virus and its potential risk factors in dairy cattle of Jimma town, southwestern Ethiopia. J Dairy Vet Anim Res. (2019) 8:11-7. doi: 10.15406/jdvar.2019.08.00235

41. Tesfaye G, Tsegaye W, Chanie M, Abinet F. Seroprevalence and associated risk factors of bovine brucellosis in Addis Ababa dairy farms. Trop Anim Health Prod. (2011) 43:1001-5. doi: 10.1007/s11250-011-9 798-0

Conflict of Interest: The authors declare that the research was conducted in the absence of any commercial or financial relationships that could be construed as a potential conflict of interest.
Publisher's Note: All claims expressed in this article are solely those of the authors and do not necessarily represent those of their affiliated organizations, or those of the publisher, the editors and the reviewers. Any product that may be evaluated in this article, or claim that may be made by its manufacturer, is not guaranteed or endorsed by the publisher.

Copyright $\odot 2021$ Tschopp, Gemechu, Wood and The ETHICOBOTS Consortium. This is an open-access article distributed under the terms of the Creative Commons Attribution License (CC BY). The use, distribution or reproduction in other forums is permitted, provided the original author(s) and the copyright owner(s) are credited and that the original publication in this journal is cited, in accordance with accepted academic practice. No use, distribution or reproduction is permitted which does not comply with these terms. 